\title{
Exogenous RNA Segments Detected Specifically in the Brain of Kuchijirosho (snout ulcer disease)-infected Fugu Takifugu rubripes: Molecular Diagnosis Tool for Kuchijirosho
}

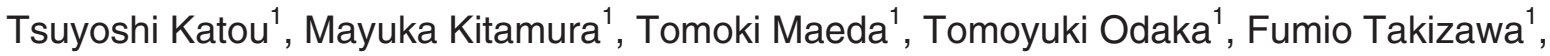 \\ Hiroaki Suetake ${ }^{1}$, Tadashi Isshiki ${ }^{2}$ and Toshiaki Miyadai ${ }^{1 *}$ \\ ${ }^{1}$ Faculty of Marine Science and Technology, Fukui Prefectural University, Fukui 917-0003, Japan \\ ${ }^{2}$ Graduate School of Bioresources, Mie University, Mie 514-8507, Japan
}

(Received September 17, 2020)

\begin{abstract}
Kuchijirosho is a lethal infectious disease of fugu Takifugu rubripes, and the causative pathogen has been predicted to be an RNA virus. Although the homogenate of kuchijirosho-affected brain is pathogenic to fugu, the suspected viral particles have not been found in the brain and the viral genome has not been isolated. We attempted to clone the cDNA of the kuchijirosho virus genome using the Rapid Determination System for Viral RNA Sequence method. Three cDNA segments of ca. 1,000 nt each, which could be parts of the viral genome, were obtained from total RNA extracted from the brains of fugu artificially infected with kuchijirosho. According to RT-qPCR, the brain had more of these three kuchijirosho-associated RNAs (KARs) than any other tissues. KARs in the brain were detected 1-2 days after injecting the homogenate of kuchijirosho-affected brain and KARs expression levels were increased rapidly until death. These results show that the detection of KARs can be sufficiently effective for the molecular diagnosis of kuchijirosho. Even if KARs are parts of the viral genome, it is unclear to which taxonomic family the kuchijirosho virus belongs, because the nucleotide sequences of KARs did not correspond to those of any other organisms including viruses.
\end{abstract}

Key words: kuchijirosho, RNA segments, virus, diagnosis, fugu, Takifugu rubripes

An epidemic of kuchijirosho (snout ulcer disease) of fugu Takifugu rubripes first occurred in aquaculture farms in Nagasaki Prefecture in 1982 (Hatai et al., 1983). Affected fish become sensitive to physical stimuli, rush around intensively, and bite other fish, after which they become exhausted and die about 10 days after infection (Miyadai et al., 2001). The pathogen of this disease was inferred to be a virus because of its filterable characteristic (Inouye et al., 1992). We attempted to purify the kuchijirosho virus by density gradient ultracentrifugation using an angiography agent, iothalamate, and estimated its density to be ca. $1.1 \mathrm{mg} / \mathrm{mL}$ (Miyadai et al., 2004). However, an amount of virus particles sufficient to analyze the viral genome and to observe viral particles has never been obtained by this method.

Although several fish cell lines did not succumb to crude kuchijirosho virus, which was the supernatant of the homogenized brains of kuchijirosho-affected fugu, the primary culture of fugu ovary (Inouye et al., 1992) and a fugu cell line, fugu eye (ATCC ${ }^{\circledR}$ CRL-2641 ${ }^{\mathrm{TM}}$ )

\footnotetext{
* Corresponding author

E-mail: miyadai@fpu.ac.jp
}

(Hashimoto et al., 2008), were susceptible to kuchijirosho virus and showed a cytopathic effect (CPE) after inoculation. However, this cell line neither produced enough particles of kuchijirosho virus nor was subjected to molecular biological analysis to determine the taxonomic classification of the pathogen. Hashimoto et al. (2008) postulated that kuchijirosho causative agent is an RNA virus because 5-fluorouracil, which inhibits both RNA and DNA synthesis, markedly suppressed kuchijirosho virus replication. In contrast, actinomycin $\mathrm{D}$, a DNA-dependent RNA polymerase inhibitor, and 5-iodo2 '-deoxyuridine (IUdR), a DNA synthesis inhibitor, evoked none of the inhibitory activity of kuchijirosho virus proliferation. Considering this experimental evidence, it seems plausible that a virus with an RNA genome is strongly involved in kuchijirosho.

In this study, we attempted to clone nucleotides associated with kuchijirosho by the Rapid Determination System for Viral RNA Sequence (RDV) method (Mizutani et al., 2007), which is based on a global analysis used to determine viral genomes with unknown nucleotide sequences. This method was thought to be suitable for the genomic analysis of kuchijirosho virus because it 
does not require purified virus particles and can determine the genomic sequence of viruses for whom no nucleotide sequences are available. Nucleotide sequences obtained from this study will not only aid in the molecular diagnosis of kuchijirosho, but will also provide fundamental insights into the future phylogenetic classification of the kuchijirosho virus, analysis of its transmission pathway, and the development of a vaccine for it.

\section{Materials and Methods}

Animals

Fugu weighing 300-500 g were bred at the Research Center for Marine Bioresources of Fukui Prefectural University in Obama, Japan. The fish were kept in $3 \mathrm{~kL}$ aquaria under natural temperature conditions, supplied with filtrated seawater, and fed with dry food pellets once a day (Nippai). The fugu were injected with a supernatant of homogenate of kuchijirosho-affected fugu brain and reared in water maintained at $25^{\circ} \mathrm{C}$. For dissection, the fugu were anesthetized with 2-phenoxyethanol, and tissues were excised out of the fish and immediately frozen in a small vessel made of aluminum foil floating on liquid nitrogen. These experiments were performed in accordance with the rules and regulations of the Animal Care and Use Committee of Fukui Prefectural University.

Inoculum

The source of the original inoculum was a preparation from a brain (approximately $0.2 \mathrm{mg}$ ) obtained from a fugu that had been naturally infected with kuchijirosho in 1993 at one of the culture farms in Wakasa Bay, Japan. The frozen brain was homogenized in $20 \mathrm{~mL}$ of Leibovitz's L-15 medium supplemented with $60 \mathrm{~mm} \mathrm{NaCl}$ (L-15 N) using a pestle in a chilled mortar containing sea sand type C, 40-80 mesh (Nacalai), and centrifuged at $17,000 \times \mathrm{g}$ for $15 \mathrm{~min}$ at $4^{\circ} \mathrm{C}$. The supernatant was filtered through a $0.22-\mu \mathrm{m}$-pore filter and stored in liquid nitrogen. The homogenates of an infected brain collected in 1993 from fugu cultured in a farm were serially passaged to fugu more than nine times, and then frozen in liquid nitrogen. The stocked kuchijirosho-affected brains were used as the inoculum in this experiment, unless otherwise noted.

$R D V$

To identify the kuchijirosho virus genome, we used a slightly modified version of the RDV method (Mizutani et al., 2007). To eliminate contamination of fuguderived DNA and RNA, $500 \mu \mathrm{L}$ of the supernatant of homogenate of kuchijirosho-affected fugu brain was treated with $1 \mathrm{U} / \mu \mathrm{L}$ of cyanase nuclease (Ribo Solutions) for $30 \mathrm{~min}$ at room temperature. The infectivity of treated samples was ascertained by inoculating into fugu by intramuscular injection.

RNA was extracted from cyanase-treated brain homogenate using ISOGEN (Nippon Gene), with DNA degradation treatment by DNase (Nippon Gene), while cDNAs were synthesized from total RNA with SuperScript III reverse transcriptase (Invitrogen) using 6-mer random primers, and amplified using GenomePlex Complete Whole Genome Amplification kit (SigmaAldrich) in accordance with the manufacturer's protocol. The final products were purified using the MonoFas DNA purification kit (GL Science).

Purified DNA was blunt-ended by Alu I (Takara), and EcoR I-Not I-BamH I Adaptor (Takara) was ligated to the DNA by DNA ligase (Takara, Ligation high ver. 2.0). An equal volume of the DNA solution was added to all of the wells of a 96-well plate, and different pairs of primers, in which four variable nucleotides were ligated to the $3^{\prime}$ end of the adaptor sequence, were added to each well. Subsequently, PCR was performed as follows: $95^{\circ} \mathrm{C}$ for $12 \mathrm{~min}$, and then 70 cycles of $72^{\circ} \mathrm{C}$ for 30 $\mathrm{s}$ and $94^{\circ} \mathrm{C}$ for $30 \mathrm{~s}$. The amplified products showing a single band on the agarose gel after electrophoresis were selected and their nucleotide sequences were determined with an ABI PRISM3100-Avant Genetic Analyzer (Applied Biosystems). Finally, the determined nucleotide sequences were analyzed with the BLAST program, IMCB FUGU Genome Project (http://www. fugu-sg.org/), and sequences similar to those of the fugu genome were eliminated from the subsequent analysis. Sequences other than those of the fugu genome were analyzed with the BLASTN and BLASTX programs of the DNA Data Bank of Japan (DDBJ). RNA segments appearing only in the tissues from kuchijirosho-affected fugu were called kuchijirosho-associated RNA (KAR) in this study.

\section{Elongation of cDNA nucleotide sequences by $3^{\prime}$ RACE}

Total RNA extracted from kuchijirosho-affected brain was subjected to ligation of a poly $(A)$ segment to the $3^{\prime}$ end of the RNA by using $E$. coli Poly $(A)$ polymerase (New England Bio Labs). Components of the reaction cocktail were as follows: $500 \mathrm{ng}$ of RNA, $1 \mathrm{~mm}$ ATP, Poly(A) Polymerase Reaction Buffer, and E. coli Poly $(A)$ polymerase. Then, reverse transcription was performed using 3' RACE CDS primer in accordance with the manual of the SMARTer ${ }^{T M}$ RACE CDNA Amplification kit (Clontech). Next, first PCR was carried out using the following primer sets: reverse UPM Universal Primer and KAR-specific forward primers (Table 1) with polymerase KOD Fx Neo (Toyobo Life Science). PCR was performed as follows: $94^{\circ} \mathrm{C}$ for 1 min; 40 cycles of $94^{\circ} \mathrm{C}$ for $30 \mathrm{~s}, 60^{\circ} \mathrm{C}$ for $30 \mathrm{~s}$, and $72^{\circ} \mathrm{C}$ for $3 \mathrm{~min}$; and finally $72^{\circ} \mathrm{C}$ for $7 \mathrm{~min}$. Nested PCR was performed using reverse Nested Universal Primer A (NUP) and the KAR-specific forward primers with the same conditions as the first PCR. 
Table 1. PCR primers for detection of KARs cloned by RDV

\begin{tabular}{|c|c|c|c|c|}
\hline KAR & Direction & Name & Nucleotide sequence & Length \\
\hline \multirow{2}{*}{ KAR-A } & forward & AF & GAGGTGACTCAAGGCAGACATC & \multirow{2}{*}{321} \\
\hline & reverse & AR & TGATCATCTCTGGGAGTTCCTCTAT & \\
\hline \multirow{2}{*}{ KAR-B } & forward & $\mathrm{BF}$ & ATCCATTAAGGAGAGTTCAGCAGTT & \multirow{2}{*}{314} \\
\hline & reverse & BR & CACACCCAАСАСАСТGТССАТАС & \\
\hline \multirow{2}{*}{ KAR-C } & forward & CF & ATGGAGGAACAAAGGGAGAAG & \multirow{2}{*}{160} \\
\hline & reverse & CR & TTTGTCGTGGGTTTTACAGTAGC & \\
\hline
\end{tabular}

Table 2. KAR specific primers for RT-qPCR

\begin{tabular}{|c|c|c|c|c|}
\hline Fragments & Direction & Name & Nucleotide sequences & Length \\
\hline \multicolumn{5}{|l|}{ RT primer } \\
\hline \multirow{2}{*}{ KAR-A } & forward & A-RTF & GCAATGGAAGACATAGCTTT & \\
\hline & reverse & A-RTR & TTTTGATATAATTGGAGCCTTTCG & \\
\hline \multirow{2}{*}{ KAR-B } & forward & B-RTF & AGATTCGTGGCTGGGTAAAAGAG & \\
\hline & reverse & B-RTR & GATTCAGTCTCCGCTTATACC & \\
\hline \multirow{2}{*}{ KAR-C } & forward & C-RTF & CCGAAAGACGTTTCCCCATA & \\
\hline & reverse & C-RTR & CCACCGCCCTGTTTCAGG & \\
\hline$\beta$-actin & & actin-RTR & GAAACATTTGCGGTGGACG & \\
\hline \multicolumn{5}{|l|}{ qPCR primer } \\
\hline \multirow{2}{*}{ KAR-A } & forward & A-qRTF & ATGGATGTAGGACACGGCAAAC & \multirow{2}{*}{176} \\
\hline & reverse & A-qRTR & ACGCTGTAGGAAAGTTGGACAC & \\
\hline \multirow{2}{*}{ KAR-B } & forward & B-qRTF & TGAAGCAATGGGAAGACACCAC & \multirow{2}{*}{127} \\
\hline & reverse & B-qRTR & ATTGCTGCCAGACATTTGCC & \\
\hline \multirow{2}{*}{ KAR-C } & forward & C-qRTF & TGTGATAGCACAACAACCCAGG & \multirow{2}{*}{103} \\
\hline & reverse & C-qRTR & GGCAATCAATGTTGTGTGGTGG & \\
\hline \multirow{2}{*}{$\beta$-actin } & forward & actin-qRTF & AAGCCAACAGGGAGAAGATGAC & \multirow{2}{*}{128} \\
\hline & reverse & actin-qRTR & AGAGTCCATGACGATACCAGTG & \\
\hline
\end{tabular}

Elongation of cDNA nucleotide sequences by 3'-adaptor ligation

Given that KARs have not been identified as singlestranded or double-stranded RNAs, specific RT primers were designed near both the $3^{\prime}$ ends of the deduced double-stranded KARs and used for cDNA synthesis to proceed toward the $3^{\prime}$ end of the known nucleotide sequence of KAR. Adaptor oligo DNA 5'-phosphorylated was ligated to the $3^{\prime}$ end of CDNA using T4 RNA/ DNA ligase (Takara). Ligated DNA was purified using FastGene $^{\mathrm{TM}}$ Gel/PCR Extraction Kit (Nippon Genetics), in accordance with the manufacturer's protocol. Purified DNA was subjected to PCR amplification using a reverse primer composed of a part of the adaptor oligo nucleotide sequence and KAR-specific forward primer designed at the further $3^{\prime}$ end of the RT primer site. Then, the amplified products were inserted into the TA cloning plasmid, $\mathrm{PCR}^{\circledR}$ II TOPO ${ }^{\circledR}$ (Invitrogen), after which $\mathrm{DH} 5 \alpha$ was transformed by the recombinant plasmid. Colonies selected by blue-white screening were subjected to plasmid extraction and determination of the nucleotide sequence.

\section{$R T-q P C R$}

RNA was extracted from nuclease-treated samples using ISOGEN II (Nippon Gene), in accordance with the supplier's manual. Assuming that both strands of KAR are present in the brain, RT primers were designed at the $3^{\prime}$ end of KAR and its complementary strand (Table 2). cDNA was synthesized from total RNA extracted from brains removed from kuchijirosho-infected or uninfected fugu. The PCR primers were designed to amplify 100 to 200 bases (Table 2). The quantitative PCR reaction mixture in a total volume of $10 \mu \mathrm{L}$ was as follows: $5 \mu \mathrm{L}$ of GoTaq Hot Start Colorless Master Mix (Promega), $0.5 \mu \mathrm{L}$ of $25 \mu \mathrm{m}$ Syto9 (Live/Dead BacLight Bacterial Viability Kit; Invitrogen), $0.5 \mu \mathrm{L}$ of $10 \mu \mathrm{M}$ forward primer solution, $0.5 \mu \mathrm{L}$ of $10 \mu \mathrm{m}$ reverse primer solution, and $0.5 \mu \mathrm{L}$ of cDNA solution. qPCR was conducted with LightCycler 480 (Roche). Thermal cycling conditions were as follows: $95^{\circ} \mathrm{C}$ for $10 \mathrm{~min}$; 45 cycles of $95^{\circ} \mathrm{C}$ for $10 \mathrm{~s}$ and $55^{\circ} \mathrm{C}$ for $30 \mathrm{~s}$; and finally $72^{\circ} \mathrm{C}$ for 7 min. Fluorescence was monitored in each step at $55^{\circ} \mathrm{C}$. After PCR amplification, melting analysis was performed. The copy number of KAR and $\beta$-actin cDNA 


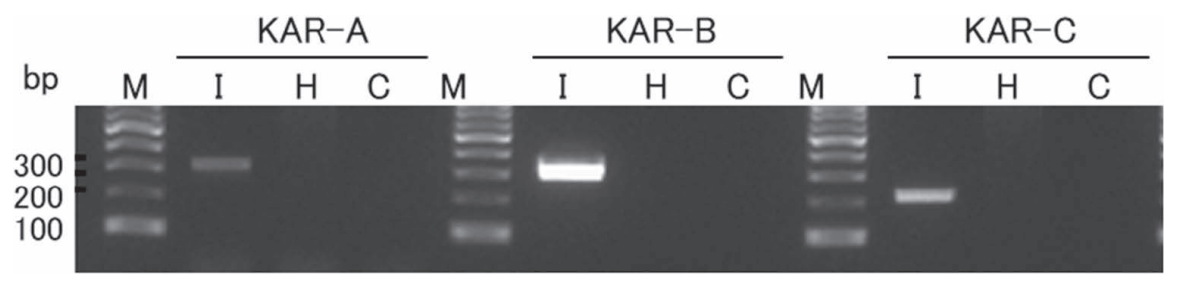

Fig. 1. RT-PCR amplification products of kuchijirosho-associated RNA (KAR). Using KAR primers designed on the basis of nucleotide sequences of cDNA cloned by RDV, PCR amplification was attempted with cDNA as templates obtained by reverse transcription using a six-base random primer. PCR products were derived from I: infected brain, $\mathrm{H}$ : healthy brain. C: no template. M: 100 bp DNA ladder markers.

in the samples was calculated based on a standard line determined from the Ct value of PCR products with a known concentration. The relative copy number of KAR cDNA was estimated by standardization to the $\beta$-actin cDNA copy number determined from the same tissue sample.

\section{RT-PCR for diagnosis of kuchijirosho}

RNA was extracted from the brain of the fish using ISOGEN II (Nippon Gene), in accordance with the supplier's manual. cDNAs were synthesized from total RNA (ca. $1 \mu \mathrm{g}$ ) with PrimeScript II reverse transcriptase (Takara) using 6-mer random primers. PCR was performed using EmeraldAmp ${ }^{\circledR}$ PCR Master Mix (Takara) and qPCR primer sets (Table 2) except those for KARB. KAR-B forward and reverse primers are BF2 (5'-CAGCTAGGGCTTTCACAGG-3') and BR2 (5'ATCCATTAAGGAGAGTTCAGCAGTT-3'), respectively, and the product size is $174 \mathrm{bp}$. The PCR schedule was as follows: $95^{\circ} \mathrm{C}$ for $3 \mathrm{~min}$; 35 cycles of $95^{\circ} \mathrm{C}$ for $30 \mathrm{~s}$, $62^{\circ} \mathrm{C}$ for $30 \mathrm{~s}$, and $72^{\circ} \mathrm{C}$ for $30 \mathrm{~s}$; and finally $72^{\circ} \mathrm{C}$ for 1 min. After agarose gel electrophoresis, DNA was preor post-stained with GelRed Nucleic Acid Stain 10000X (Merck).

\section{Homology analysis}

Homology analysis was carried out using the BLAST programs for nucleotide sequences and Expasy program of Swiss Institute of Bioinformatics for protein sequences (http://web.expasy.org/translate/).

\section{Results}

KAR

From the RDV cloning, three cDNA segments of 321,314 , and 160 nucleotides in length were obtained and named KAR-A, -B, and $-\mathrm{C}$, respectively. To determine whether the three RNA fragments were expressed in a kuchijirosho-specific manner, RT-PCR was performed using RNA extracted from infected and uninfected brains as templates, in which random primer and KAR-specific primers (Table 1) were applied for RT and PCR, respectively. The results showed that KAR was expressed in the brain of kuchijirosho-affected fugu, but not in the uninfected one (Fig. 1).

Extension of the KAR segment toward the $3^{\prime}$ end was carried out using SMARTer ${ }^{\mathrm{TM}}$ RACE cDNA Amplification kit. Furthermore, another elongation method, adaptor ligation to the $3^{\prime}$ end of cDNA followed by PCR using a gene-specific/adaptor primer set, was performed. The whole nucleotide sequences determined in these two methods were registered in the DDBJ database (accession numbers LC504499, LC504500, and LC504501 for KAR-A, -B, and -C, respectively). The lengths of the cDNA nucleotide sequences of KAR-A, -B, and -C are 1,581, 1,791, and 1,410 , respectively. Because there was variation in the nucleotide sequences at the $5^{\prime}$ end of KAR-B among the clones, of all sequences determined, the longest sequence of $288 \mathrm{nt}$ was registered. At the $3^{\prime}$ end of all of the KARs, 16-20 nucleotides, 5'-ATXCAAAAATATGC $[X]_{n}$ ACC-3' $(n=0-4)$, are conserved.

\section{$K A R-A,-B$, and $-C$ were expressed mainly in the brain}

To estimate the amount of KARs in the organs of the infected fugu, RT-qPCR was performed using the primers shown in Table 2. The highest expression level was found in the brain, while there was somewhat high expression in the spinal cord. Very weak expression was detected in the eye, gills, kidney, spleen, PBL, and liver (Table 3). These findings supported the description that kuchijirosho virus mainly proliferates or at least accumulates in the brain.

Expression of KAR in the brain during the course of kuchijirosho infection

To clarify when KARs appear upon kuchijirosho virus infection, KARs in the brain were quantified by RT-qPCR. Fugu were intramuscularly injected with the supernatant of homogenate of fugu brain affected by kuchijirosho. After 4 days post-injection (dpi), the fish became violent in response to stimuli such as netting in the tank and, from $7 \mathrm{dpi}$, some individuals began to puff out their abdomens, while from $8 \mathrm{dpi}$, some individuals died. KARs were slightly but clearly detected 1-2 dpi (Fig. 2A), and those in the brain increased rapidly at 5 dpi (Fig. 2B). 
Table 3. Relative expression of KAR in each tissue of fugu

\begin{tabular}{lccc}
\hline & KAR-A & KAR-B & KAR-C \\
\hline Brain & $151.45 \pm 139.84$ & $260.42 \pm 93.37$ & $24.84 \pm 18.53$ \\
Spinal cord & $52.25 \pm 13.44$ & $294.76 \pm 133.47$ & $4.23 \pm 4.66$ \\
Eye & $0.05 \pm 0.05$ & $0.23 \pm 0.32$ & $0.00 \pm 0.00$ \\
Mouth & $0.00 \pm 0.00$ & $0.01 \pm 0.01$ & $0.00 \pm 0.00$ \\
Gill & $0.16 \pm 0.26$ & $12.17 \pm 18.91$ & $0.01 \pm 0.01$ \\
Fore gut & $0.00 \pm 0.00$ & $0.00 \pm 0.00$ & $0.00 \pm 0.00$ \\
Hind gut & $0.00 \pm 0.00$ & $0.01 \pm 0.02$ & $0.00 \pm 0.00$ \\
Rectum & $0.00 \pm 0.00$ & $0.00 \pm 0.00$ & $0.00 \pm 0.00$ \\
Thymus & $0.00 \pm 0.00$ & $0.00 \pm 0.01$ & $0.00 \pm 0.00$ \\
Head kidney & $0.16 \pm 0.27$ & $0.12 \pm 0.12$ & $0.01 \pm 0.01$ \\
Body kidney & $0.03 \pm 0.04$ & $0.05 \pm 0.07$ & $0.01 \pm 0.00$ \\
Spleen & $0.33 \pm 0.28$ & $5.21 \pm 8.70$ & $0.06 \pm 0.08$ \\
PBL* & $0.01 \pm 0.02$ & $0.20 \pm 0.34$ & $0.01 \pm 0.02$ \\
Liver & $0.01 \pm 0.02$ & $0.02 \pm 0.02$ & $0.00 \pm 0.00$ \\
Heart & $0.00 \pm 0.00$ & $0.00 \pm 0.00$ & $0.00 \pm 0.00$ \\
Muscle & $0.00 \pm 0.00$ & $0.00 \pm 0.00$ & $0.00 \pm 0.00$ \\
Skin & $0.00 \pm 0.00$ & $0.00 \pm 0.00$ & $0.00 \pm 0.00$ \\
Testis & $0.00 \pm 0.00$ & $0.00 \pm 0.00$ & $0.00 \pm 0.00$ \\
\hline
\end{tabular}

Copy numbers of KAR were normalized by those of $\beta$-actin mRNA. Analysis was performed using tissues dissected from 3 fishes.

*PBL: peripheral blood leucocytes
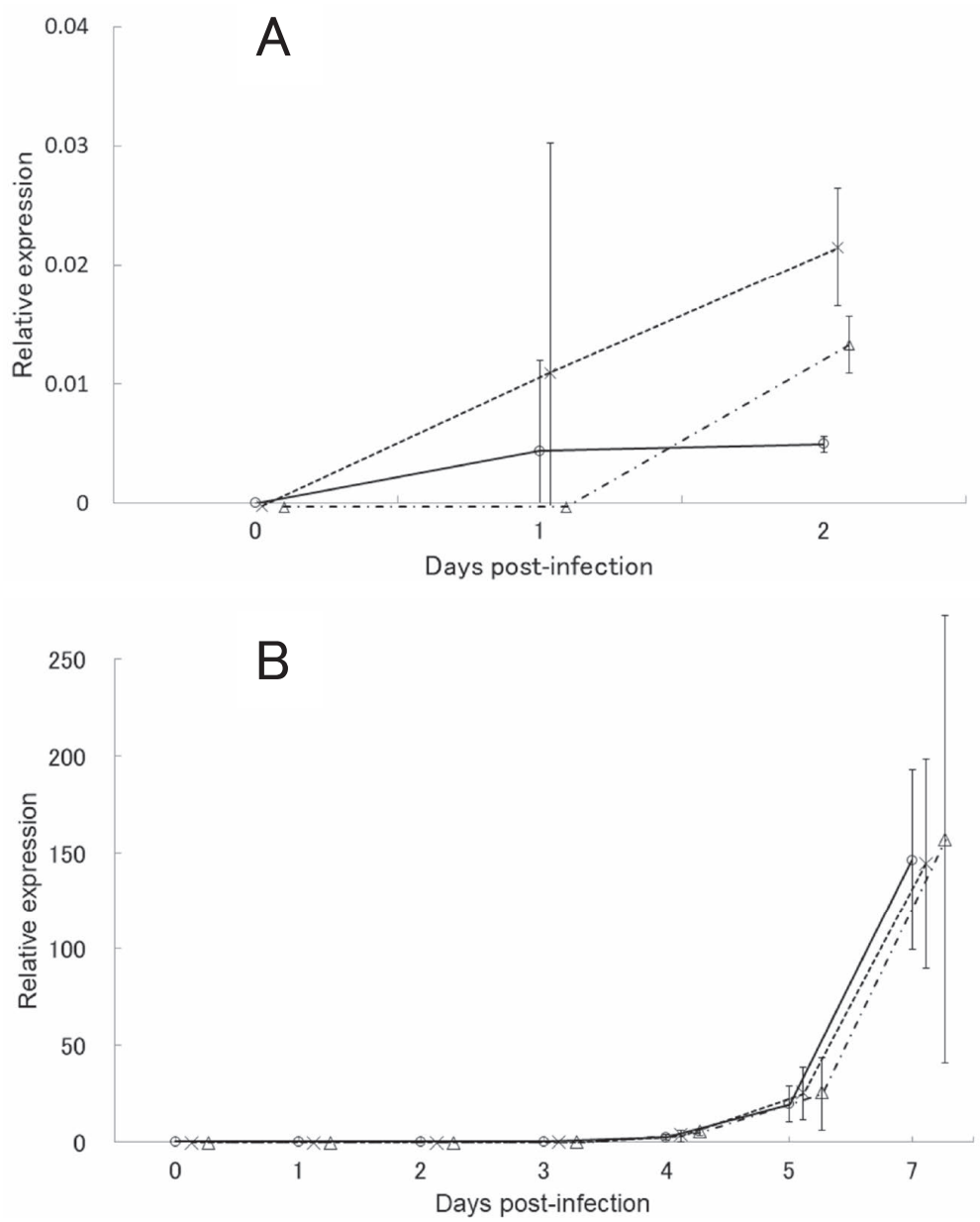

Fig. 2. Increase in the amount of KARs through the progression of kuchijirosho. The levels of KAR-A, $-B$, and $-C$ in the brains of fugu injected with the supernatant of homogenate of kuchijirosho-affected brain into the muscle were determined by RT-qPCR. Copy number was calculated based on a standard line using a known amount of KAR DNA. One of the housekeeping genes, $\beta$-actin, was used for normalization of the RT-qPCR data. Fig. 2A indicates RT-qPCR data 2 days postinfection (dpi) and Fig. 2B shows the data 7 dpi; straight line: KAR-A, dotted line: KAR-B, dot-dashed line: KAR-C. 


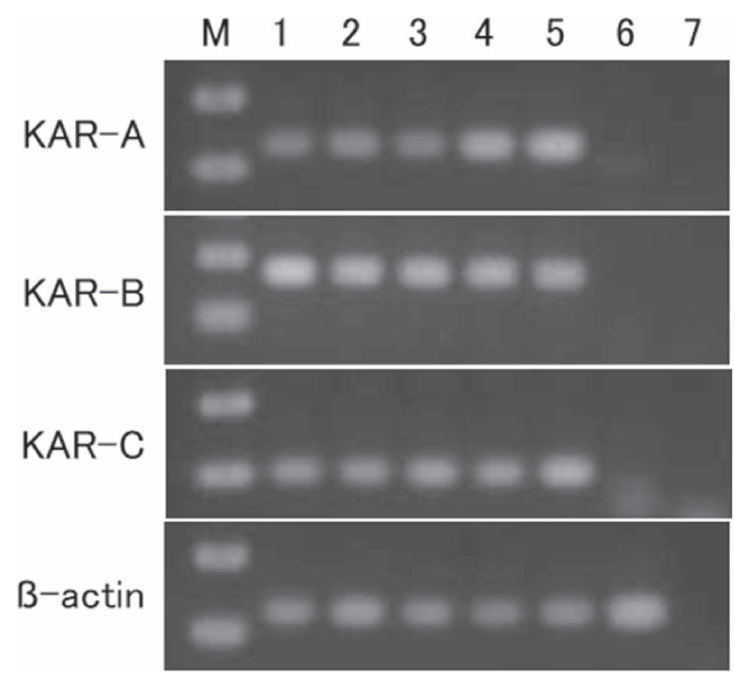

Fig. 3. Diagnosis of kuchijirosho by detecting KARs. KARs were detected in the brains of spontaneously diseased fugu by RT-PCR. The template RNA was extracted from the brain. Lanes 1-5 are infected brains. Lane 1 is an infected brain serially in vivo passaged from original infected brains collected in 1993 . Lanes 2-5 are the brains of diseased fugu from a fish farm in 2020 , lane 6 is a healthy fugu brain from the same farm, and lane 7 is a negative control without the addition of cDNA. The fragments are between $100 \mathrm{bp}$ and 200 bp marker bands (lane M).

\section{Diagnosis of kuchijirosho by KAR detection}

In August 2020, fugu showing symptoms of kuchijirosho appeared at a different farm other than one where fugu infected with kuchijirosho in 1993 had been raised. KAR-A, -B, and -C were detected by RT-PCR in the brains of the spontaneously diseased fugu sampled from the farm in 2020 (Fig. 3, lanes 2-5) as well as those of kuchijirosho-affected fugu used in other experiments in this study (Fig. 3, lane 1). No KARs were detected in healthy fish (Fig. 3, lane 6) of the same seedling origin raised in the same farms where an outbreak of kuchijirosho occurred in 2020.

\section{Discussion}

In this study, we cloned the cDNA of three kuchijirosho-associated RNA segments, designated as KARs in this paper, which were abundantly expressed in the brains of kuchijirosho-affected fugu. KARs were thought to be derived from the causative pathogen of kuchijirosho, not the fugu genome. Therefore, the detection of KARs is practically useful as a molecular diagnostic method for kuchijirosho.

Hashimoto et al. (2008) have already suggested that kuchijirosho virus is an RNA virus from the findings of in vitro experiments to inhibit virus production using inhibitors of nucleic acid synthesis. In our experiment using total DNA extracted from kuchijirosho-affected brain of fugu as a template for PCR to detect KARs, no
KAR DNA segments were amplified, which indicates that KARs are not derived from DNA, including the genomes of DNA viruses, bacteria, fungi, fugu, or any other organisms with a DNA-based genome. Therefore, the present study supports the assertion that the kuchijirosho virus is an RNA virus.

Inouye (1988) indicated that the kuchijirosho virus is a DNA virus because, when a homogenate of kuchijirosho-affected fugu brain was treated with DNase, the infectivity of the pathogen of kuchijirosho was completely lost. Although the symptoms of kuchijirosho caused by infection with kuchijirosho virus used in this study are similar to those described in other reports (Hatai et al., 1983; Nakauchi et al., 1985; Wada et al., 1985, 1986; Inoue et al., 1986, 1992; Miyadai et al., 2001; Takami et al., 2007a, 2007b, 2007c), more than one virus species might be involved in the development of kuchijirosho. We detected KARs in fugu showing symptomatic signs similar to kuchijirosho that had broken out at an aquaculture farm in 2020 in Japan (Fig. 3). In October 2015, KARs were also detected from the brains of fugu, which were cultured in another fish farm, with kuchijirosho-like disease (data not shown). These findings suggest that a disease brought about by the expression and increase of KARs in the brain is widespread in fugu farms in Japan and that this disease would be kuchijirosho.

To predict the translation initiation site and the CDS of KAR-A, -B, and $-C$, we used the prediction software NetStart (http://www.cbs.dtu.dk/services/NetStart/). The numbers of amino acids in the longest protein encoded in KAR-A, -B, and - $C$ (accession numbers $\mathrm{BBO} 25536, \mathrm{BBO} 25537$, and $\mathrm{BBO} 25538$ ) are 415,478 , and 384 , respectively. BLASTN and BLASTP analyses of KAR-A, $-B$, and $-C$ and their predicted proteins showed that none of the nucleotide and amino acid sequences identical to KARs and predicted KAR proteins were listed in databases including viruses. Therefore, kuchijirosho virus would be a novel type of virus.

Upon searching for functional domains based on the three-dimensional structure of the deduced KAR proteins, the analytical software SWISS-MODEL (https:// swissmodel.expasy.org/) showed that 35 amino acids near the C-terminal region of KAR-A protein resemble part of the functional domain (202 aa) of bacterial methyltransferase (3JWJ_A; Chan et al., 2009). In the case of KAR-B protein, a structure with 278 aa near the $\mathrm{N}$-terminal region resembles part of the RNA-directed RNA polymerase catalytic subunit of influenza B virus (AAU94857; 752 aa) (Lukarska et al., 2017). It is suggested that KAR-B has some structural similarity to a viral RNAdependent RNA polymerase. SWISS-MODEL predicted a 3D structure consisting of 91 aa of KAR-C that resembles part of glutamine-fructose-6-phosphate aminotransferase (6R41_A, 687 aa) (Ruegenberg et al., 2020). Nonstructural protein 5 in flavivirus has 
methyltransferase activity and is responsible for $\mathrm{N}-7$ and $2^{\prime}-\mathrm{O}$ methylation of the viral RNA 5'-cap structure (Koonin, 1993; Egloff et al., 2002; Ray et al., 2006; Zhou et al., 2007). However, the regions are only small fractions of the proteins presented by the predicted software program; moreover, amino acid identity in these regions of KAR-A, $-\mathrm{B}$, and $-\mathrm{C}$ proteins is only $2.86 \%, 23.38 \%$, and $13.19 \%$, respectively. To ascertain whether the deduced KAR proteins actually exist in kuchijiroshoaffected fugu brain, we need to examine the antigenantibody reaction using anti-recombinant KAR proteins.

Inouye et al. (1992) reported that, when a primary culture of fugu ovary cells was inoculated with the supernatant of homogenate of the brain or kidney dissected from kuchijirosho-affected fugu, the former induced a CPE more severely than the latter. Quantitative comparison of KARs in various tissues by RT-PCR in this study (Table 3) supported the observation by Inouye et al. (1992), which suggests that kuchijirosho virus proliferates predominantly in the brain rather than in other tissues. KARs were slightly expressed in the terminal parts of the nerves such as in the mouth, gut, and other tissues, so kuchijirosho virus might migrate through axons from the brain to other tissues, like herpesviruses (Smith, 2012). Therefore, testing for the presence of KARs in the brain may enable the diagnosis of kuchijirosho.

During the course of experimental infection of kuchijirosho, KAR-A, -B, and C could be detected 1-2 dpi by RT-qPCR amplification and increases of their levels were associated with the worsening of symptoms until death (Fig. 2). Brains excised from fugu 2 dpi developed the ability to cause kuchijirosho when their homogenate was injected to healthy fugu, which strongly suggests that KARs are associated with the pathogenesis of kuchijirosho. The use of KAR-specific primers for cDNA synthesis allows us to diagnose kuchijirosho before the onset of the disease, and random primers are sufficient to detect KARs in fugu that have developed kuchijirosho. In earlier studies, histological damage in the brain of fugu infected with kuchijirosho was seen in the form of nucleolus condensation of giant neuronal cells in the region of the brain stem (Nakauchi et al., 1985; Wada et al., 1985; Miyadai et al., 2001). By a preliminary in situ hybridization experiment, we detected KARs in the cells distributed over almost all of the brain (data not shown). Such whole-brain encephalopathy would explain why kuchijirosho develops with a fulminant course to death.

We predicted that kuchijirosho virus may be a flavivirus from the following evidences: the density $(1.095 \mathrm{~g} /$ $\mathrm{mL}$ ) of the infectious fraction (Miyadai et al., 2004), nucleic acid synthesis (Hashimoto et al., 2008), electron microscope image of infected primary cultured cells (Isshiki and Miyadai, 2019) and characteristics of the viral particle (Inouye et al., 1992; Hashimoto et al.,
2008). Taking account of the virological evidence, it could be speculated that KARs are viral genomes or have some association with a virus. However, because KARs are not compatible with the genomes of any viruses, including flavivirus, listed in databases, to ascertain whether KARs are viral genomes and what functions the encoded proteins have, further experiments are needed. Takami et al. (2007a) demonstrated that $0.3 \%$ formalin-treated kuchijirosho-affected brain homogenate retained infectivity, which indicates that the causative agent of kuchijirosho might have unusually robust resistance to chemical inactivation treatment. Considering the characteristics evidenced so far, kuchijirosho virus is likely to be quite different from previously identified viruses.

\section{Acknowledgments}

This work was supported by JSPS KAKENHI Grant Numbers JP23580261 and JP15K07558. We also thank Edanz for editing the English text of a draft of this manuscript.

\section{References}

Chan, C. M., C. Zhou, J. S. Brunzelle and R. H. Huang (2009) Structural and biochemical insights into 2'-O-methylation at the 3'-terminal nucleotide of RNA by Hen1. Proc. Natl. Acad. Sci. U. S. A., 106, 17699-17704.

Egloff, M. P., D. Benarroch, B. Selisko, J. L. Romette and B. Canard (2002): An RNA cap (nucleoside-2'-O-)-methyltransferase in the flavivirus RNA polymerase NS5: crystal structure and functional characterization. EMBO J., 21, 2757-2768.

Hashimoto, E., T. Miyadai, M. Ohtani, S.-I. Kitamura and M.-J. Oh (2008): Proliferation of kuchijirosho causative agent in a fugu-derived cell line. J. Fish Dis., 6, 443-449.

Hatai, K., N. Yasunaga and S. Yasumoto (1983): Unknown disease of cultured puffer. Bull. Nagasaki Pref. Inst. Fish., 9, 59-61. (In Japanese)

Inouye, K. (1988): Studies on "kuchijiro-sho" in tiger puffer (Takifugu rubripes). PhD dissertation. University of Hokkaiko, Japan. (In Japanese)

Inouye, K., S. Yasumoto, N. Yasunaga and I. Takami (1986): Isolation of a virus from cultured tiger puffer, Takifugu rubripes, infected with "Kuchijiro-sho" and its pathogenicity. Fish Pathol., 21, 129-130. (In Japanese)

Inouye, K., K. Yoshikoshi and I. Takami (1992): Isolation of causative virus from cultured tiger puffer (Takifugu rubripes) affected by kuchijirosho (snout ulcer disease). Fish Pathol., 27, 97-102.

Isshiki, T. and T. Miyadai (2019): Electron microscopy of the kuchijirosho (snout ulcer disease) causative agent in cell culture derived from fugu Takifugu rubripes. Aquaculture, 500, 141-147.

Koonin, E. V. (1993): Computer-assisted identification of a putative methyltransferase domain in NS5 protein of flaviviruses and lambda 2 protein of reovirus. J. Gen. Virol., 74, 733-740.

Lukarska, M., G. Fournier, A. Pflug, P. Resa-Infante, S. Reich, N. Naffakh and S. Cusack (2017): Structural basis of an essential interaction between influenza polymerase and 
Pol II CTD. Nature, 541, 117-121.

Miyadai, T., S. Kitamura, H. Uwaoku and D. Tahara (2001): Experimental infection of several fish species with the causative agent of kuchijirosho (snout ulcer disease) derived from the tiger puffer Takifugu rubripes. Dis. Aquat. Organ., 47, 193-199.

Miyadai, T., E. Hashimoto, K. Hashimoto, T. Watari, M. Ohtani and D. Tahara (2004): Partial purification of Kuchijirosho causative agent by sodium iotalamate density gradient centrifugation. Fish Pathol., 39, 213-214.

Miyanari, Y., K. Atsuzawa, N. Usuda, K. Watashi, T. Hishiki, M. Zayas, R. Bartenschlager, T. Wakita, M. Hijikata and K. Shimotohno (2007): The lipid droplet is an important organelle for hepatitis C virus production. Nature Cell Biol., 9, 1089-1097.

Mizutani, T., D. Endoh, M. Okamoto, K. Shirato, H. Shimizu, M. Arita, S. Fukushi, M. Saijo, K. Sakai, C. K. Lim, M. Ito, R. Nerome, T. Takasaki, K. Ishii, T. Suzuki, I. Kurane, S. Morikawa and H. Mishimura (2007): Rapid genome sequencing of RNA viruses. Emerg. Infect. Dis., 13, 322-324.

Nakauchi, R., T. Miyazaki and T. Shiomitsu (1985): A histopathological study on "kuchijiro-sho" of tiger puffer. Fish Pathol., 20, 475-479. (In Japanese with English abstract)

Ray, D., A. Shah, M. Tilgner, Y. Guo, Y. Zhao, H. Dong, T. Deas, Y. Zhou, H. Li and P. Y. Shi (2006): West Nile virus 5 -cap structure is formed by sequential guanine $\mathrm{N}-7$ and ribose 2'-O methylations by nonstructural protein $5 . \mathrm{J}$. Virol., 80, 8362-8370.

Ruegenberg, S., M. Horn, C. Pichlo, K. Allmeroth, U. Baumann and M. S. Denzel (2020): Loss of GFAT-1 feedback regulation activates the hexosamine pathway that modulates protein homeostasis. Nature commun., 11, 687.

Smith, G. (2012): Herpesvirus transport to the nervous system and back again. Annu. Rev. Microbiol., 66, 153-176.

Takami, I., T. Nishizawa and M. Yoshimizu (2007a): Experiments on induction of protection against kuchijirosho of tiger puffer. Fish Pathol., 42, 67-69. (In Japanese with English abstract)

Takami, I., T. Nishizawa and M. Yoshimizu (2007b): Detection of kuchijirosho associated proteins by Western blot with sera of tiger puffer which survived kuchijirosho. Fish Pathol., 42, 29-34. (In Japanese with English abstract)

Takami, I., T. Nishizawa and M. Yoshimizu (2007c): Induction of kuchijirosho in yellowtail by infection with the brain homogenate of affected tiger puffer. Fish Pathol., 42, 35-39. (In Japanese with English abstract)

Wada, S., Y. Fujimaki, K. Hatai, S. Kubota and M. Isoda (1985): Histopathological findings of cultured tiger puffer Takifugu rubripes naturally infected with "kuchijiro-sho". Fish Pathol., 20, 495-500. (In Japanese with English abstract)

Wada, S., K. Hatai and S. Kubota (1986): Histopathological findings of tiger puffer Takifugu rubripes artificial infected with "kuchijiro-sho". Fish Pathol., 21, 101-104. (In Japanese with English abstract)

Zhou, Y., D. Ray, Y. Zhao, H. Dong, S. Ren, Z. Li, Y. Guo, K. Bernard, P. Y. Shi and H. Li (2007): Structure and function of flavivirus NS5 methyltransferase. J. Virol., 81, 38913903. 